\title{
Desain Pembelajaran Pendidikan Islam Berbasis Neurosains untuk Menjaga Postur Tubuh Siswa
}

\author{
${ }^{* 1}$ Sukma Dewi Hapsari, ${ }^{2}$ Suyadi \\ ${ }^{12}$ Magister Pendidikan Agama Islam, Universitas Ahmad Dahlan, Jl. Pramuka, \\ Yogyakarta \\ *sukma2107052032@webmail.uad.ac.id
}

Tanggal Submitt: 23/11/2022 Tanggal diterima:15/01/2022 Tanggal Terbit:30/01/2022

\begin{abstract}
Learning in Indonesia has been very less concerned with the condition of students, especially aspects of ergonomics that determine comfort, aesthetics and function. The research aims to analyze the design of neuroscience-based Islamic educational learning, which pays attention to the ergonomic dimensions of students when studying. This research approach is a qualitative type of literature. The source of this research data is the publication of both articles in journals and books indexed synta 1-6. Data collection techniques are carried out by tracing references in google scholar data base through keywords of learning design, Islamic education, neuroscience, posture and sitting position. The collected data is then analyzed descriptively which includes display, reduction, interpretation and meaning creativity. The results showed that so far learning has not been designed with attention to ergonomics and anthropometrics. Therefore the design of tables and chairs in learning should pay attention to ten anthropometric aspects, namely height, weight, body mass index, poplitea height, butt length, and hip width. This is necessary in order to produce an ideal or comfortable table and chair output for students in learning, so that it will not experience so-called back pain and spinal abnormalities.
\end{abstract}

Keywords: Ergonomics, Islamic Education, Learning Design, Neuroscience

\begin{abstract}
Abstrak: Pembelajaran di Indonesia selama ini sangat kurang memperhatikan kondisi dari siswa, khususnya aspek ergonomi yang menentukan kenyamanan, estetika dan fungsi. Penelitian ini bertujuan untuk menganalisis desain pembelajaran pendidikan Islam berbasis neurosains, yang memperhatikan dimensi ergonomi siswa ketika belajar. Pendekatan penelitian ini adalah kualitatif jenis kepustakaan. Sumber data penelitian ini merupakan publikasi baik artikel pada jurnal maupun buku yang terindeks sinta 1-6. Teknik pengumpulan data dilakukan dengan menelusuri referensi dalam data base google cendekia melalui kata kunci desain pembelajaran, ergonomi, neurosains, pendidikan Islam, postur tubuh. Data yang terkumpul kemudian dianalisis deskriptif yang meliputi display, reduksi, interpretasi dan meaning creativity. Hasil penelitian menunjukan bahwa selama ini pembelajaran belum didesain dengan memperhatikan ergonomi dan antropometrik. Oleh karena itu desain meja dan kursi dalam pembelajaran hendaknya memperhatikan sepuluh aspek antropometrik, yaitu tinggi badan, berat badan, indeks massa tubuh, tinggi poplitea, panjang pantat, dan lebar pinggul. Hal ini diperlukan agar bisa menghasilkan output meja dan kursi yang ideal atau nyaman digunakan untuk siswa dalam belajar, sehingga tidak akan mengalami yang namanya nyeri punggung dan kelainan tulang belakang.

Kata Kunci: Desain Pembelajaran, Ergonomi, Neurosains, Pendidikan Islam, Postur Tubuh
\end{abstract}

\section{Pendahuluan}

Desain pembelajaran PAI berbasis neurosains yang memperhatikan postur tubuh siswa saat belajar ini masih minim dilakukan, sehingga menjadi masalah yang 
berkelanjutan. Hal ini dibuktikan dengan data faktual di daerah Surabaya yang mengindap jenis penyakit musculoskletal atau kelainan pada system yang terdiri dari otot, persendian dan tulang sebesar 7,93\% atau 245.000 jiwa pada tahun 2019. ${ }^{1}$ Akibatnya terjadi gangguan atau kelainan perkembangan fisik dan terjadinya kelainan tulang belakang (chronic) di masa mendatang. Jika dibiarkan, maka dampak 10-20 tahun mendatang akan ada kelainan pada struktur tulang punggung, dimana terdapat tiga jenis gangguan tulang punggung yaitu, lordosis, kifosis dan skoliosis, oleh karena itu perlu adanya edukasi dalam bentuk materi pembelajaran dan tindakan pelaksanaan saat pembelajaran dalam artian guru mendesain ruang kelas yang memperhatikan aspekaspek egronomis untuk menjaga postur tubuh siswa. ${ }^{2}$

Siswa merupakan golongan generasi penerus bangsa yang kedepannya akan melangkah untuk membangun dan ikut berpartisipasi dalam kebaikan serta kemajuan bangsa Indonesia. ${ }^{3}$ Tentunya hal tersebut tidak bisa diraih secara instant. Banyak proses yang harus dilalui oleh anak, yang utama seperti belajar dan sekolah. Berbicara tentang sekolah, guru merupakan orang tua kedua siswa di sekolah yang mempunyai andil besar dalam mencetak penerus bangsa Indonesia, setelah orang tua siswa yang di rumah. ${ }^{4}$ Dalam Pendidikan Islam harus senantiasa mengutamakan dan mengembangkan berbagai desain pembelajaran baik secara intelektual maupun praktik. ${ }^{5}$ Maka perlu adanya pengembangan dari berbagai model pembelajaran sebagai wujud pendidikan Islam yang selalu terbuka dan berinovasi guna tercapainya insan kamil sebagaimana yang dicitacitakan oleh bangsa dan negara. Namun, seharusnya bukan hanya fokus pada akademik saja, tetapi semua hal yang ada pada diri siswa harus dioptimalkan dan dijaga ruhani serta jasmani agar bisa memberikan kontribusi yang berguna bagi orang banyak. ${ }^{6}$ Sudah sewajarnya orang-orang yang disekitar siswa harus memperhatikan segala aspek dalam pembelajaran untuk pertumbuhan dan perkembangannya.

Oleh karena itu, guru pendidikan agama Islam sangat dianjurkan untuk melakukan pembelajaran dengan pendekatan neurosains atau ilmu akal agar pembelajaran bisa sekaligus mencakup pengembangan potensi siswa dalam pembentukan karakter, emosional dan rasionalitasnya, seperti IQ, EQ, SQ, MaQ dan Multiple Intellegence. ${ }^{7}$ Hal ini berkaitan dengan pembelajaran pendidikan Islam yang menciptakan pertumbuhan siswa

${ }^{1}$ Dinas Kesehatan Surabaya, "Jenis Penyakit Musculoskletal," Website Resmi Dinas Kesehatan Surabaya, 2019, http://dinkes.surabaya.go.id/portalv2/.

2 Diana Mayasari and Fitria Saftarina, "Ergonomi Sebagai Upaya Pencegahan Musculoskletal Disorders Pada Pekerja," Jurnal Kedokteran Universitas Lampung, 2016.

3 Angga Winata Harahap and Hamidah D, "Optimalisasi Peran Guru Dalam Proses Pembelajaran,” Jurnal Serunai Administrasi Pendidikan, 2019, https://doi.org/10.37755/jsap.v8i1.202.

${ }^{4}$ Utkarsh Karki, Gunjan Dhonju, and Arun Raj Kunwar, "Parenting during the COVID-19 Pandemic," Journal of the Nepal Medical Association, 2020, https://doi.org/10.31729/jnma.5319.

5 A Z Ayunda, "Keefektifan Pembelajaran Pendidikan Islam Secara Daring Di Tengah Situasi Social Distancing Akibat Penyebaran Covid-19 "Di Madrasah Aliyah Negeri 2 ...," Tarbawy: Jurnal Pendidikan Islam, 2020.

${ }^{6}$ Susanna Loeb et al., "The Development Of Energy Efficiency Estimation System For Domestic Housing By Using Quality Function Deployment Approach Ptta," Open Review of Educational Research (2014).

7 Imroatum Muhimmah and Suyadi Suyadi, "Neurosains Dan Spiritualitas Dalam Pendidikan Islam,” TADRIS: Jurnal Pendidikan Islam, 2020, https://doi.org/10.19105/tjpi.v15i1.2880. 
yang sehat baik mental, fisik, sosial, spiritual, dan emosi. ${ }^{8}$ Pada point sehat fisik inilah menjadi hal yang sering dilupakan, sehingga dalam penelitian ini akan membahas postur tubuh yang berkaitan tentang sehat fisik dengan teori antropometrik. Dengan ini peneliti menganalisis desain pembelajaran pendidikan Islam berbasis neurosains, khususnya penataan postur tubuh saat belajar dengan menggunakan teori antropometrik yang mencakup beberapa aspek, diantaranya desain pembelajaran berbasis otak, desain meja dan kursi untuk menjaga postur tubuh siswa agar tidak mengalami kelainan tulang.

Sejauh ini penelitian tentang desain pembelajaran berbasis neurosains yang memperhatikan postur tubuh siswa masih sedikit dilakukan. Penelitian Saifurrahman menunjukan bahwa, tiga skema desain pembelajaran berbasis neurosains, yaitu: pembukaan (pencahayaan pendar, denyut berpikir, seting kelas yang menantang, dll), inti (sink setting/ ambak, ekspositori, diskusi, role play dan assesmen), dan penutup (enker, dan sejenisnya). ${ }^{9}$ Namun penelitian itu masih menyisakan persoalan bahwa, proses pelaksanaan pembelajaran secara keseluruhan dilakukan di dalam kelas dengan posisi duduk, jika terlalu lama maka tidak bisa mengontrol dan akan berpengaruh ke postur tubuh siswa. Oleh karena itu, diperlukan sebuah desain pembelajaran berbasis neurosains yang memperhatikan postur tubuh siswa yang menjadi solusi untuk pencegahan mengalami penyakit kelainan tulang di masa depan dan siswa merasakan kenyamanan saat belajar, sehingga konsentrasi belajar dan prestasi belajar pun turut meningkat.

\section{Metode Penelitian}

Pendekatan penelitian ini adalah kualitatif jenis library research atau kepustakan. Penelitian kualitatif kepustakaan yakni menelaah dan menganalisis buku-buku yang berkaitan langsung maupun tidak langsung yakni dengan mengumpulkan dan mengkaji berbagai pustaka yakni buku-buku yang relevan dan tulisan ilmiah lainnya yang berhubungan dengan tujuan penelitian. ${ }^{10}$ Data dilakukan dengan menelusuri referensi dalam data base google cendekia melalui kata kunci desain pembelajaran, ergonomi, neurosains, pendidikan Islam, postur tubuh. Metode ini digunakan untuk memperoleh data yang bersifat teoritis. ${ }^{11}$ Alasan memilih kepustakaan, karena di masa pandemi COVID-19 ini ruang geraknya terbatas dan banyak prosedur yang harus dilakukan untuk melakukan penelitian lapangan, sehingga kepustakaan ini memudahkan peneliti dalam mencari data yang diperlukan dalam menyelesaikan penelitian, yaitu berupa artikel, buku, ensiklopedia dan lain sebagainya. ${ }^{12}$

Sumber data pada penelitian ini berasal dari buku-buku, jurnal dan karya ilmiah lain yang relevan dengan pembahasan yang merupakan komponen dasar pada penelitian ini, sehingga memungkinkan untuk mempermudah dalam proses penelitian. Berdasarkan

\footnotetext{
${ }^{8}$ Moch Fadhli Zhafir Maftuh, "Pendidikan Agama Islam," Banjarbaru: Grafika Wangi Kalimantan, 2017.

9 Saifurrahman and Suyadi, "Desain Pembelajaran Keagamaan Islam Berbasis Neurosains," ALMURABBI: Jurnal Studi Kependidikan Dan Keislaman 6, no. 1 (2019): 55-73.

${ }^{10}$ Yaniawati, "Penelitian Studi Kepustakaan."

${ }^{11}$ Poppy Yaniawati, "Penelitian Studi Kepustakaan," Penelitian Kepustakaan (Liberary Research), 2020.

12 Prof.Dr. Sugiyono, metode penelitian kuantitatif, kualitatif,dan R\&D, Alfabeta, cv. (2016).
} 
sumbernya, data dibedakan menjadi dua, yaitu data primer dan data sekunder. ${ }^{13}$ Sumber data primer, yaitu data yang diperoleh dari sumber asli yang memuat informasi atau data tersebut. Dalam hal ini, yang menjadi sumber data primer adalah materi yang berkaitan dengan materi neurosains, pendidikan Islam, postur tubuh dan posisi tubuh. Sumber data sekunder yaitu data yang diperoleh dari sumber yang bukan asli, yang memuat informasi atau data tersebut, sumber data sekunder digunakan untuk mendukung dan melengkapi data primer yang telah ditemukan. Untuk memperluas kajian serta memperdalam pembahasan, penulis juga menggunakan beberapa karya tulis lain yang memiliki relevansi dengan objek. Mencakup publikasi ilmiah berupa buku-buku, artikel dan hasil penelitian yang berkaitan dengan konsep bidang yang dikaji, yaitu desain pembelajaran pendidikan Islam berbasis neurosains dan postur tubuh saat belajar.

\section{Pembahasan}

Hasil penelitian ini disajikan dalam dua temuan pokok. Pertama kebiasaan postur tubuh siswa saat duduk dalam pembelajaran dan desain meja kursi siswa berbasis neurosains.

\section{A. Kebiasaan Postur Tubuh Siswa saat Duduk dalam Pembelajaran}

Siswa saat menjalani pembelajaran di dalam kelas sebagian besar waktunya digunakan dengan posisi duduk dan akhirnya menjadi kebiasaan. Jika diperhatikan secara seksama, posisi duduk yang dilakukan siswa itu bermacam-macam. Ada yang bersandar, siap tegak, membungkuk, dll. ${ }^{14}$ Namun yang paling banyak dilakukan yaitu duduk dengan membungkuk, posisi tersebut jika dibiarkan terus menerus akan mengakibatkan yang namanya kelainan tulang belakang yang akan terjadi jangka panjang, yaitu 10-20 tahun mendatang. ${ }^{15}$

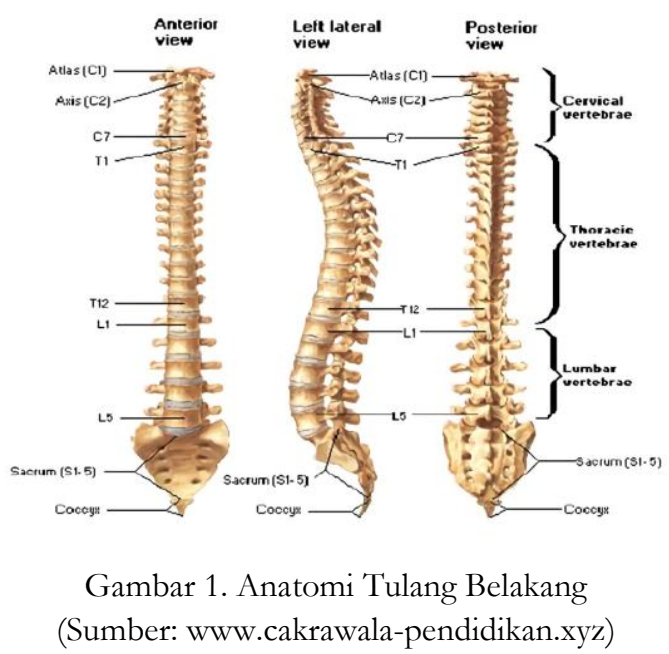

13 Milya Sari and Asmendri, "Metode Penelitian Kepustakaan (Library Research)," Penelitian Kepustakaan (Library Research) Dalam Penelitian Pendidikan IPA, 2018.

${ }^{14}$ Aan Pravo Albarado and Viarti Eminita, "Pengaruh Kebiasaan Belajar Terhadap Prestasi Belajar Siswa Di Mts Khazanah Kebajikan," Jurnal Pendidikan Matematika Dan Matematika Fibonacci, 2020. Pekerja."

${ }^{15}$ Mayasari and Saftarina, "Ergonomi Sebagai Upaya Pencegahan Musculoskletal Disorders Pada 
Terlihat dari gambar anatomi tulang belakang pada tahap awal perkembangan terdapat 33 jenis tulang belakang. Ketika seorang anak tumbuh, beberapa tulang belakang di daerah sacral dan cocoggeal menyatu. ${ }^{16}$ Oleh karena itu tulang belakang pada manusia dewasa terdiri dari 26 tulang belakang yang terdiri dari:

1. 7 cervical vertebrae, terletak di regio leher.

2. 12 thoracic vertebrae, terletak di posterior dari thoracic cavity.

3. 5 lumbar vertebrae, menopang punggung bawah.

4. 1 sacrum, terdiri dari 5 bagian tulang sacral yang menyatu.

5. $1 \operatorname{coccy} x$, terdiri dari 4 bagian tulang coccygeal yang menyatu.

Jika dilihat dari sisi anterior atau posterior, bentuk tulang belakang tampak lurus. Namun ketika dilihat dari sisi lateral, terlihat 4 lengkungan kecil yang disebut kurva normal. Kurva cervical dan lumbar terlihat cembung sementara pada kurva thoracic dan sacral terlihat cekung. ${ }^{17}$ Kurva pada tulang belakang ini meningkatkan kekuatan tubuh sehingga membantu menjaga keseimbangan ketika berdiri, menahan guncangan ketika berjalan,dan membantu melindungi vertebra ketika terjadi fraktur. ${ }^{18}$
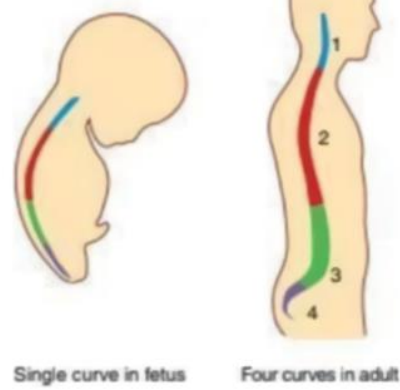

Gambar 2. Perbedaan Kurva Tulang Belakang ketika Masa Janin dan Dewasa

(Sumber: www.cakrawala-pendidikan.xyz)

Gambar di atas terlihat perbedaan pada kurva pada regio thoracal dan sacral disebut kurva primer karena sejak masa bayi sampai dewasa tetap mempertahankan bentuk kelengkungan asli embrionik berbentuk cekung. ${ }^{19}$ Sementara kurva regio cervical dan lumbar berubah bentuk menjadi cembung ketika proses perkembangan seperti bergerak memegang kepala, duduk, berdiri, dan berjalan. ${ }^{20}$ Beberapa kondisi mekanis yang tidak fisiologis dapat membuat perubahan bentuk pada tulang vertebra sehingga terjadi

${ }^{16}$ Rizky Suganda, Endro Sutrisno, and Irawan Wisnu Wardana, “Anatomi Dan Fisiologi Tulang Belakang," Journal of Chemical Information and Modeling, 2013.

17 Totok Budi Santoso Widiastuti, Ciptari, "Pengaruh Core Stability Exercise Terhadap Kekuatan Otot-Otot Lumbal Akibat Pemakaian Sepatu Hak Tinggi Pada Sales Promotion Girl," Fakultas Ilmu Kesehatan Universitas Muhammadiyah Surakarta, 2013.

${ }^{18}$ Eri Satria, Sri Rahayu, and Jubaedi Jubaedi, "Rancang Bangun Media Pembelajaran Interaktif Anatomi Tubuh Pada Manusia Berbasis Android,” Jurnal Algoritma, 2021, https://doi.org/10.33364/algoritma/v.18-1.839.

${ }^{19}$ Rahkmad Rosadi, "Hubungan Kebiasaan Duduk Terhadap Terjadinya Skoliosis Pada Anak Usia 11-13 Tahun Di SD Pabelan Kartasura Surakarta," Jurnal Keperawatan, 2009.

${ }^{20}$ Edwina Nabila, "Efektivitas Skoliometer Sebagai Alat Deteksi Dini Skoliosis," Health \& Medical Journal, 2020, https://doi.org/10.33854/heme.v2i1.297. 
ketidakseimbangan tubuh yang akhirnya mengalami kelainan tulang belakang dan biasanya ditandai dengan timbul rasa nyeri. ${ }^{21}$ Kelainan tulang belakang yang selama ini populer ada tiga, sebagai berikut.

1. Kifosis

Kelainan pada tulang belakang ini dapat terlihat dari postur tubuh yang bungkuk. Hal ini disebabkan oleh tulang belakang yang melengkung ke depan hingga nampak bungkuk. Bahkan kondisi ini juga dapat menyebabkan tulang belakang terlihat menonjol di punggung. Penyebab kifosis biasanya adalah tulang keropos, terlalu berat membawa beban, sikap tubuh yang salah, radang sendi, spina bifida, tumor pada tulang belakang, infeksi tulang belakang, kifosis kongenital, penyakit Scheuermann, dan osteoporosis. Kifosis juga bisa menimbulkan rasa sakit pada tulang belakang. ${ }^{22}$

2. Lordosis

Penderita lordosis memiliki tulang belakang yang melengkung secara berlebihan ke arah depan pada bagian punggung bawah. Kondisi lordosis sering disebut juga dengan istilah swayback dan membuat bokong terlihat lebih menonjol. Tulang belakang normal memang melengkung, tapi pada penderita lordosis lengkungan tersebut terlalu menjorok ke depan. Tak jarang juga kondisi ini menyebabkan rasa sakit. Kelainan tulang belakang ini bisa disebabkan oleh pergeseran ruas tulang, obesitas, cedera tulang, postur tubuh yang buruk, distrofi otot, osteoporosis, dan diskitis atau peradangan pada ruang antara tulang belakang. ${ }^{23}$

3. Skoliosis

Dalam kondisi ini, tulang belakang melengkung secara berlebihan ke samping. Kebanyakan kasus skoliosis cenderung ringan, tapi kondisinya dapat memburuk seiring bertambahnya usia. Kelainan tulang ini menyebabkan tulang belakang bengkok dan bisa memicu kelumpuhan atau gangguan fungsi paru-paru. Masalah ini dikarenakan posisi lekukan tulang belakang yang mampu mengurangi jumlah ruang di dada. Bahkan, salah satu jenis skoliosis yang disebut levoscoliosis menyebabkan tulang belakang bengkok ke sisi kiri tubuh dan menyerupai huruf C. ${ }^{24}$

Oleh karena itu, dalam pembelajaran guru bukan hanya saja terfokus pada materi pembelajaran, tetapi juga harus memperhatikan postur tubuh siswa saat duduk untuk menghindari siswa mengalami kelainan tulang belakang. Karena secara filosofis, hakikat pendidikan adalah membentuk manusia sempurna atau Insan kamil. ${ }^{25}$ Dalam perspektif

\footnotetext{
${ }^{21}$ Nia Kurniawati, Noorhana Fadilla, and Mohammad Ali, "Perbandingan Pengaruh Self Correction Dan Task Oriented Exercise Dengan Klapp Exercise Terhadap Derajat Skoliosis Siswa SMP Dengan Skoliosis Idiopatik Tipe C," Quality : Jurnal Kesehatan, 2019, https://doi.org/10.36082/qjk.v13i2.78.

22 Rema Ira Prastiwi, Rizka Risy W, and Sri Lestari, "Postur Kifosis Menyebabkan Gangguan Keseimbangan Statis Lansia," Jurnal Keterapian Fisik, 2020, https://doi.org/10.37341/jkf.v5i2.225.

${ }^{23}$ Guang Ming Guo et al., "Cervical Lordosis in Asymptomatic Individuals: A Meta-Analysis," Journal of Orthopaedic Surgery and Research, 2018, https://doi.org/10.1186/s13018-018-0854-6.

24 James J Heckman, Rodrigo Pinto, and Peter A. Savelyev, "Skoliosis," Angewandte Chemie International Edition, 6(11), 951-952., 2019.

${ }^{25}$ M Ramli, "Hakikat Pendidikan Dan Peserta Didik," Tarbiyah Islamiyah, 2015.
} 
psikologis, manusia sempurna adalah manusia yang berkembang seluruh potensi atau kecerdasannya, baik potensi jasmani, rohani, maupun akal. ${ }^{26}$ Seluruh potensi manusia bertumpu pada otaknya. ${ }^{27}$ Ilmu yang mempelajari otak adalah neurosains. ${ }^{28}$ Oleh karena itu, pendidikan dan neurosains dapat dipadukan dengan perekat psikologi. ${ }^{29}$ Dari penjelasan aspek filosofis ini sudah terlihat bahwa postur tubuh juga termasuk ke dalam hakikat pendidikan Insan kamil dalam unsur jasmani, sehingga postur tubuh ini juga termasuk poin penting dalam pembelajaran.

Secara teoritis terdapat kesamaan persepsi antara psikologi, pendidikan, dan neurosains sehingga ketiganya dapat dipadukan. ${ }^{30}$ Konsep manusia sempurna yang mempunyai unsur-unsur jasmani, rohani, dan akal, sama dengan konsep psikologi tentang kognitif, afektif, dan psikomotorik. ${ }^{31}$ Demikian pula dengan neurosains yang mengandung unsur-unsur otak rasional, otak emosional dan otak spiritual. ${ }^{32}$

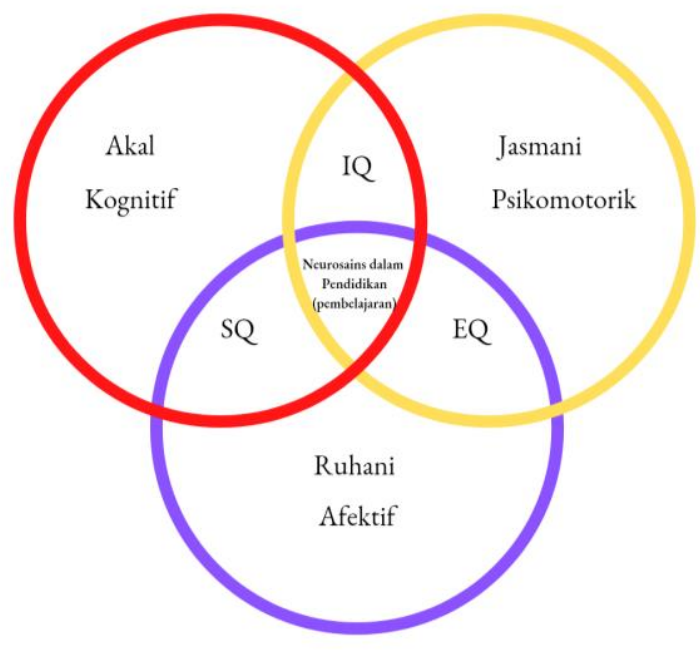

Gambar 3. Model Integration Neuroscience Education

(Sumber: Buku Teori Pembelajaran Anak Usia Dini)

Gambar di atas menjelaskan bahwa pembelajaran merupakan gabungan antara neurosains, pendidikan, dan psikologi. Neurosains spesifikasi pada otak rasional, otak emosional dan otak spiritual. Pendidikan dispesifikan pada pengembangan jasmani,

\footnotetext{
${ }^{26}$ Meta Malihatul Maslahat, "Manusia Holistik Dalam Perspektif Psikologi Dan Tasawuf," Syifa AlQulub, 2019, https://doi.org/10.15575/saq.v\%vi\%i.5242.

27 Suyadi and Hendro Widodo, "Millennialization of Islamic Education Based on Neuroscience in the Third Generation University in Yogyakarta Indonesia," Qudus International Journal of Islamic Studies, 2019, https://doi.org/10.21043/qijis.v7i1.4922.

28 Suyadi, "Integrasi Pendidikan Islam Dan Neurosains Dan Implikasinya Bagi Pendidikan Dasar (PGMI)," Al-Bidayah, 2012.

${ }^{29}$ Suyadi Suyadi, "Hybridization of Islamic Education and Neuroscience: Transdisciplinary Studies of 'Aql in the Quran and the Brain in Neuroscience," Dinamika Ilmu, 2019, https://doi.org/10.21093/di.v19i2.1601.

30 Suyadi, "Integrasi Pendidikan Islam Dan Neurosains Dan Implikasinya Bagi Pendidikan Dasar (PGMI)."

31 Suyadi Suyadi, "Pendidikan Islam Anak Usia Dini Dalam Perspektif Neurosains: Robotik, Akademik, Dan Saintifik," Edukasia: Jurnal Penelitian Pendidikan Islam, 2019, https://doi.org/10.21043/edukasia.v13i2.3255.

32 Suyadi, Teori Pembelajaran Anak Usia Dini, ed. Nita Nur Muliawati, 4th ed. (Bandung: PT. Remaja Rosdakarya, 2017).
} 
rohani, dan akal. Psikologi dispesifikan pada kognitif afektif dan psikomotorik. Semua unsur tersebut dikombinasikan dalam kesatuan efektif antara filosofis, teoritis, dan implementasi. Artinya, neurosains pendidikan tidak hanya sekedar konsep teoritis yang sifatnya masih filosofis, tetapi dapat diterapkan oleh guru secara praktis-empiris. ${ }^{33}$ Dalam konteks pendidikan agama Islam, neurosains pendidikan mempunyai makna penting karena nafs, qolb, aql, dan rub ternyata tidak bermakna apa-apa tanpa melibatkan diskursus neurosains. ${ }^{34}$ Dengan demikian, dalam perspektif islam, hakikat pendidikan adalah mencetak Insan Kamil. Insan Kamil tersusun dari berbagai unsur, salah satunya yaitu jasmani. Untuk itu guru harus berintegrasi dengan neurosains, agar mengetahui solusi dari permasalahan postur tubuh siswa saat pembelajaran.

\section{B. Desain Meja dan Kursi Siswa Berbasis Neurosains}

Lembaga sekolah berkewajiban untuk menyediakan fasilitas sarana dan prasarana untuk para siswa yang bersekolah, seperti gedung sekolah, lapangan, ruang kelas, lemari, papan tulis, buku, meja, kursi, dan masih banyak lagi. ${ }^{35}$ Pada pembahasan kali ini peneliti akan hanya membahas fasilitas sarana yang selalu dipakai oleh siswa, yaitu meja dan kursi. Di pembahasan sebelumnya ternyata dengan intensitas siswa yang terlalu sering duduk saat pembelajaran mengakibatkan postur tubuhnya menjadi tidak ideal, adanya kelainan tulang belakang dan timbulnya nyeri punggung. Hal ini menurut peneliti ada yang salah dari cara duduk siswa dan meja kursi yang masih belum ideal untuk digunakan dalam pembelajaran, sehingga perlu adanya inovasi desain meja kursi untuk pembelajaran agar siswa nyaman saat belajar dan di masa mendatang tidak mengalami kelainan tulang belakang.

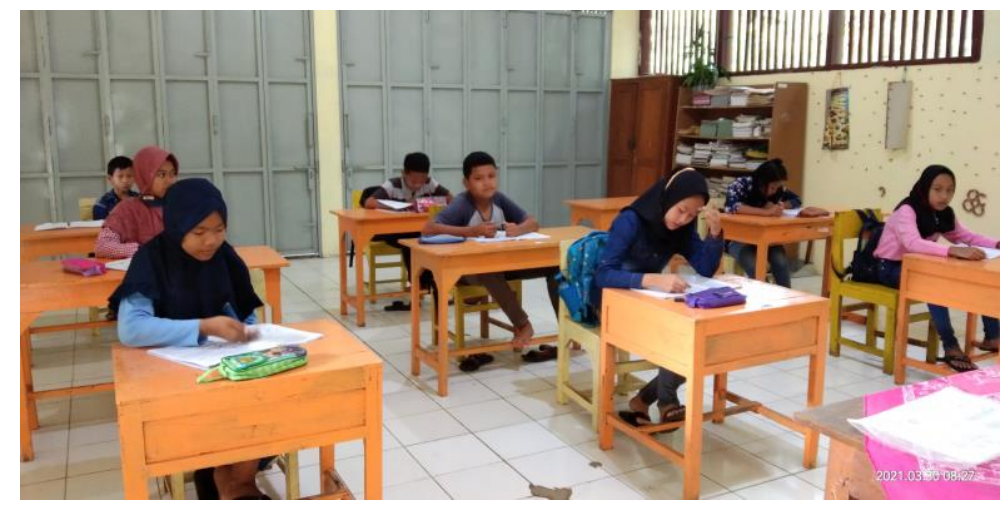

Gambar 4. Meja dan Kursi yang digunakan

Siswa untuk Belajar

(Sumber: Dokumentasi pribadi di SDN 1 Johunut Kampus Mengajar Angkatan 1 tahun 2021)

Gambar di atas memperlihatkan desain meja dan kursi yang selama ini digunakan oleh siswa untuk belajar di sekolah. Sangat ironis sekali bahwa siswa-siswa saat belajar

\footnotetext{
${ }^{33}$ Muhimmah and Suyadi, "Neurosains Dan Spiritualitas Dalam Pendidikan Islam."

${ }^{34}$ Suyadi, Teori Pembelajaran Anak Usia Dini.

35 Tia Fajartriani and Wawan Karsiwan, "Manajemen Pengadaan Sarana Prasarana Sekolah," Jurnal Educatio FKIP UNMA, 2021, https://doi.org/10.31949/educatio.v7i1.907.
} 
harus merasakan nyeri punggung. ${ }^{36}$ Padahal siswa tersebut merupakan penerus generasi bangsa Indonesia ini, seharusnya pemerintah harus menyiapkan sarana meja dan kursi dengan pertimbangan yang matang agar tidak menimbulkan gejala-gejala yang tidak baik untuk tubuh siswa. ${ }^{37}$

Peneliti di sini menemukan dalam posisi duduk yang tidak ergonomis diakibatkan oleh rancangan alat yang tidak sesuai dengan antropometrik penggunanya, sehingga mempengaruhi kinerja penggunanya. Keluhan dini dialami siswa juga dapat menimbulkan penyakit akibat posisi duduk yang tidak ergonomis menyebabkan keluhan pegal yang dapat mengganggu perkembangan tubuh murid untuk jangka waktu panjang. Oleh karena itu, sekolah wajib memperhatikan tentang kesehatan serta kenyamanan murid dengan cara menyesuaikan fasilitas sekolah seperti meja dan kursi sesuai kebutuhan penggunanya. Pendekatan ini dikenal dengan istilah pendekatan ergonomi. Salah satu peralatan yang biasa digunakan yaitu meja dan kursi yang harus sesuai ukuran tubuh penggunanya, sehingga membuat nyaman dalam menggunakannya. ${ }^{38}$

Meja dan kursi merupakan dua fasilitas penting yang diperlukan oleh murid dalam mendukung kegiatan mereka di kelas. Fasilitas tersebut haruslah memiliki bentuk dan ukuran yang sesuai dengan dimensi tubuh para murid agar kondisi belajar dan mengajar yang lebih baik dapat terwujud. Jika sikap duduk anak tidak benar seperti membungkuk ke depan, maka dapat mengakibatkan tulang belakang anak akan terganggu. ${ }^{39}$ Dengan demikian meja dan kursi sekolah harus didesain ulang sesuai dengan ukuran tubuh anak atau ergonomis. Meja dan kursi sekolah yang ergonomis akan membuat anak merasa aman, nyaman dan sehat sehingga tidak menimbulkan keluhan muskuloskeletal. Sebaliknya, jika meja dan kursi tidak ergonomis akan menimbulkan berbagai dampak negatif baik dalam jangka panjang maupun jangka pendek seperti pemakainya akan cepat merasakan lelah, nyeri dan mengalami keluhan muskuloskeletal.

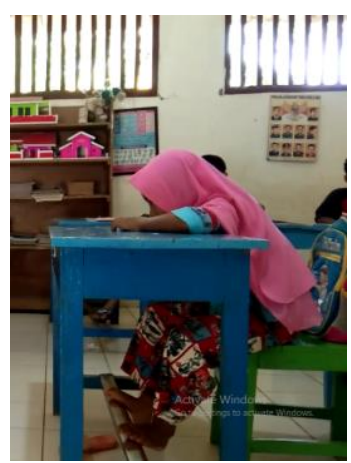

Gambar 5. Siswa membungkuk saat pembelajaran

(Sumber: Dokumentasi pribadi di SDN 1 Johunut Kampus Mengajar Angkatan 1 tahun 2021)

\footnotetext{
${ }^{36}$ Farida Umamah, Nurul Kamariyah, and Firdaus Firdaus, “Analisis Faktor Yang Mempengaruhi Keluhan Nyeri Punggung Pada Siswa Di SMP Laboratorium UNESA Surabaya,” Jurnal Surya, 2019, https://doi.org/10.38040/js.v11i02.36.

${ }^{37}$ Harahap and D, "Optimalisasi Peran Guru Dalam Proses Pembelajaran."

38 Pande Wayan Mustika I Made Sutajaya, "Ergonomi Dalam Pembelajaran Menunjang Profesionalisme Guru Di Era Global,” JPI (Jurnal Pendidikan Indonesia), 2016, https://doi.org/10.23887/jpi-undiksha.v5i1.8933.

${ }^{39}$ Fajartriani and Karsiwan, "Manajemen Pengadaan Sarana Prasarana Sekolah."
} 
Dari gambar di atas terlihat terlalu rendahnya kursi dibandingkan tubuh siswa kelas 3 mengakibatkan siswa harus senantiasa dalam posisi membungkuk ketika membaca atau menulis. Kondisi ini mengakibatkan ketidaknyamanan dalam proses belajar karena menimbulkan keluhan pegal di beberapa bagian tubuh seperti bagian punggung, pinggang, leher bagian atas, siku kiri dan lutut kanan, selain itu kebisaan membungkuk dapat mengakibatkan tubuh menjadi lebih bungkuk. ${ }^{40}$

Dalam penelitian Samuel A. Oyewole, Joel M. Haight, dan Andris Freivalds telah merancang sebuah desain meja dan kursi antropometrik yang dianalisis dengan mempertimbangkan tinggi badan, berat badan, indeks massa tubuh, tinggi poplitea, panjang bokong, dan lebar pinggul. ${ }^{41}$
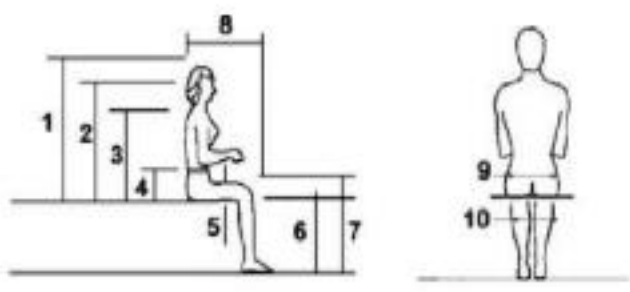

\begin{tabular}{|c|l|}
\hline 1 & Sitting Height \\
\hline 2 & Eye Height \\
\hline 3 & Shoulder Height \\
\hline 4 & Eloow Rest Height \\
\hline 5 & Thigh Ciearance \\
\hline 6 & Popliteal Height (Stod Height) \\
\hline 7 & Knee Height \\
\hline 3 & Buttock-Popliteal Length \\
\hline 9 & Hip Breasth \\
\hline 10 & Knee-to-Knee Breadth \\
\hline
\end{tabular}

Gambar 6. Aspek Pertimbangan membuat Desain Ukuran Meja dan Kursi (Sumber: isiarticles.com dan Buku Inovasi Pendidikan Anak Usia Dini)

Dari ilustrasi desain yang telah dibuat Samuel dan kawan-kawan, memperlihatkan bahwa seharusnya desain meja dan kursi untuk pembelajaran harus memperhatikan 10 aspek, yaitu tinggi duduk (sitting height), tinggi mata( eye height), tinggi bahu( shoulder height), tinggi sandaran siku (elbow rest height), panjang paha (thigh clerance), tinggi bangku(stool height), setinggi lutut (knee height), panjang pantat (buttock length), lebar pinggul (bip breadth), dan lebar lutut (knee to knee breadth). ${ }^{42}$ Maka dari itu menurut peneliti desain yang ideal untuk meja dan kursi pembelajaran hendaknya disesuaikan dengan postur tubuh siswa. Pertimbangan lain yang harus diperhatikan yaitu berat dari meja dan kursi yang tentunya

40 Suyadi Suyadi, "Perencanaan Dan Asesmen Perkembangan Pada Anak Usia Dini," Golden Age: Jurnal Ilmiah Tumbuh Kembang Anak Usia Dini, 2017, https://doi.org/10.14421/jga.2016.11-06.

41 Samuel A. Oyewole, Joel M. Haight, and Andris Freivalds, "The Ergonomic Design of Classroom Furniture/Computer Work Station for First Graders in the Elementary School," International Journal of Industrial Ergonomics, 2010, https://doi.org/10.1016/j.ergon.2010.02.002.

42 Oyewole, Haight, and Freivalds. 
harus lebih ringan dari siswa agar mudah memindah dan menatanya. ${ }^{43}$ Kemudian permukaan meja haruslah miring dan disesuaikan dengan tinggi siswa, agar siswa bisa tetap menjaga postur tubuh tegak dalam posisi duduk, sehingga meminimalisir gerakan membungkukkan badan saat belajar dan terhindar dari yang namanya nyeri punggung serta kelainan tulang belakang di masa mendatang.

\section{Catatan Akhir}

Proses pembelajaran di Indonesia ini diatur dalam sistem pendidikan sesuai dengan standar-standar yang telah ditetapkan dan disahkan. Termasuk juga sarana meja dan kursi, namun yang disayangkan meja dan kursi yang digunakan selama ini belum ideal untuk digunakan oleh siswa, khususnya siswa 5-12 tahun. Dengan meja dan kursi yang digunakan sekarang bisa menyebabkan yang namanya kelainan tulang belakang dan nyeri punggung, sehingga siswa yang seharusnya belajar dengan nyaman harus terganggu konsentrasinya karena menahan rasa sakit. Maka dari itu hendaknya desain meja dan kursi di sekolah perlu dilakukan perbaikan dengan menerapkan 10 aspek antropometrik. Penelitian ini terdapat limitasi berupa data yang didapatkan dari sumber online seperti artikel, sebagian gambar didapatkan dari penelitian terdahulu dan sebagian diambil langsung oleh peneliti di dalam kelas. Saran peneliti untuk penelitian selanjutnya diharapkan bisa meneliti tentang pengaruh sarana meja dan kursi untuk konsentrasi belajar siswa.

\section{Daftar Rujukan}

Albarado, Aan Pravo, and Viarti Eminita. "Pengaruh Kebiasaan Belajar Terhadap Prestasi Belajar Siswa Di Mts Khazanah Kebajikan.” FIBONACCI: Jurnal Pendidikan Matematika Dan Matematika Fibonacci, 6(2), 167-174, 2020.

Ayunda, A Z. "Keefektifan Pembelajaran Pendidikan Islam Secara Daring Di Tengah Situasi Social Distancing Akibat Penyebaran Covid-19 "Di Madrasah Aliyah Negeri 2 ...." Tarbany: Jurnal Pendidikan Islam, 7(2), 99-112, 2020.

Fajartriani, Tia, and Wawan Karsiwan. "Manajemen Pengadaan Sarana Prasarana Sekolah.” Jurnal Educatio FKIP UNMA, 7(1), 162-168, 2021. https://doi.org/10.31949/educatio.v7i1.907.

Guo, Guang Ming, Jun Li, Qing Xun Diao, Tai Hang Zhu, Zhong Xue Song, Yang Yang Guo, and Yan Zheng Gao. "Cervical Lordosis in Asymptomatic Individuals: A Meta-Analysis." Journal of Orthopaedic Surgery and Research, 13(1), 1-7, 2018. https://doi.org/10.1186/s13018-018-0854-6.

Harahap, Angga Winata, and Hamidah D. "Optimalisasi Peran Guru Dalam Proses Pembelajaran." Jurnal Serunai Administrasi Pendidikan, 8(1), 154-160, 2019. https://doi.org/10.37755/jsap.v8i1.202.

Heckman, James J, Rodrigo Pinto, and Peter A. Savelyev. "Skoliosis." Angewandte Chemie International Edition, 6(11), 951-952., 2019.

I Made Sutajaya, Pande Wayan Mustika. "Ergonomi Dalam Pembelajaran Menunjang Profesionalisme Guru Di Era Global.” JPI (Jurnal Pendidikan Indonesia), 5(1), 82-96, 2016. https://doi.org/10.23887/jpi-undiksha.v5i1.8933.

Karki, Utkarsh, Gunjan Dhonju, and Arun Raj Kunwar. "Parenting during the COVID-

${ }^{43}$ Suyadi, Sumaryati, and Dwi Hastuti, Inovasi Pendidikan Anak Usia Dini, 1st ed. (Yogyakarta: UAD Press, 2019). 
19 Pandemic." Journal of the Nepal Medical Association, 58(231), 957, 2020. https://doi.org/10.31729/jnma.5319.

Kurniawati, Nia, Noorhana Fadilla, and Mohammad Ali. "Perbandingan Pengaruh Self Correction Dan Task Oriented Exercise Dengan Klapp Exercise Terhadap Derajat Skoliosis Siswa SMP Dengan Skoliosis Idiopatik Tipe C." Quality : Jurnal Kesehatan, 13(2), 82-90, 2019. https://doi.org/10.36082/qjk.v13i2.78.

Loeb, Susanna, Luke C. Miller, Katharine O. Strunk, \& Bailey. L. Sirota. E., Brian W. Lagotte, Brian W. Lagotte, Mohd Fahridzakki, et al. "The Development Of Energy Efficiency Estimation System For Domestic Housing By Using Quality Function Deployment Approach Ptta." Open Review of Educational Research, 79, 513-519, 2014.

Maftuh, Moch Fadhli Zhafir. "Pendidikan Agama Islam." Banjarbaru: Grafika Wangi Kalimantan, 2017.

Maslahat, Meta Malihatul. "Manusia Holistik Dalam Perspektif Psikologi Dan Tasawuf." Syifa Al-Qulub, 4(1), 2019. https://doi.org/10.15575/saq.v\%vi\%i.5242.

Mayasari, Diana, and Fitria Saftarina. "Ergonomi Sebagai Upaya Pencegahan Musculoskletal Disorders Pada Pekerja." Jurnal Kedokteran Universitas Lampung, 1(2), 369-379, 2016.

Muhimmah, Imroatum, and Suyadi Suyadi. "Neurosains Dan Spiritualitas Dalam Pendidikan Islam." TADRIS: Jurnal Pendidikan Islam, 15(1), 68-87, 2020. https://doi.org/10.19105/tjpi.v15i1.2880.

Nabila, Edwina. "Efektivitas Skoliometer Sebagai Alat Deteksi Dini Skoliosis." Health \& Medical Journal, 2(1), 58-61, 2020. https://doi.org/10.33854/heme.v2i1.297.

Oyewole, Samuel A., Joel M. Haight, and Andris Freivalds. "The Ergonomic Design of Classroom Furniture/Computer Work Station for First Graders in the Elementary School." International Journal of Industrial Ergonomics, 40(4), 437-447, 2010. https://doi.org/10.1016/j.ergon.2010.02.002.

Prastiwi, Rema Ira, Rizka Risy W, and Sri Lestari. "Postur Kifosis Menyebabkan Gangguan Keseimbangan Statis Lansia." Jurnal Keterapian Fisik, 5(2), 139-145, 2020. https://doi.org/10.37341/jkf.v5i2.225.

Ramli, M. "Hakikat Pendidikan Dan Peserta Didik." Tarbiyah Islamiyah, 5(1), 2015.

Rosadi, Rakhmad. Hubungan Pola Sikap Duduk Terhadap Terjadinya Skoliosis Pada Anak Usia 11-13 Tahun di SDN Pabelan. 2009. PhD Thesis. Universitas Muhammadiyah Surakarta.

Saifurrahman, and Suyadi. "Desain Pembelajaran Keagamaan Islam Berbasis Neurosains." AL-MURABBI: Jurnal Studi Kependidikan Dan Keislaman 6, no. 1 (2019): 55-73.

Sari, Milya, and Asmendri. "Metode Penelitian Kepustakaan (Library Research)." Penelitian Kepustakaan (Library Research) Dalam Penelitian Pendidikan IPA, 2018.

Satria, Eri, Sri Rahayu, and Jubaedi Jubaedi. "Rancang Bangun Media Pembelajaran Interaktif Anatomi Tubuh Pada Manusia Berbasis Android.” Jurnal Algoritma, 18(1), 69-76, 2021. https://doi.org/10.33364/algoritma/v.18-1.839.

Suganda, Rizky, Endro Sutrisno, and Irawan Wisnu Wardana. "Anatomi Dan Fisiologi Tulang Belakang." Journal of Chemical Information and Modeling, 2013.

Sugiyono, Prof.Dr. metode penelitian kuantitatif, kualitatif,dan R\&D, Alfabeta, cv. (2016).

Surabaya, Dinas Kesehatan. "Jenis Penyakit Musculoskletal." Website Resmi Dinas Kesehatan Surabaya, 2019. http://dinkes.surabaya.go.id/portalv2/.

Suyadi. "Integrasi Pendidikan Islam Dan Neurosains Dan Implikasinya Bagi Pendidikan Dasar (PGMI)." Al-Bidayah, 4(1), 2012.

—. Teori Pembelajaran Anak Usia Dini. Edited by Nita Nur Muliawati. 4th ed. 
Bandung: PT. Remaja Rosdakarya, 2017.

Suyadi, Sumaryati, and Dwi Hastuti. Inovasi Pendidikan Anak Usia Dini. 1st ed. Yogyakarta: UAD Press, 2019.

Suyadi, Suyadi. "Hybridization of Islamic Education and Neuroscience: Transdisciplinary Studies of 'Aql in the Quran and the Brain in Neuroscience." Dinamika Ilmu, 19(2), 237-249, 2019. https://doi.org/10.21093/di.v19i2.1601.

_. "Pendidikan Islam Anak Usia Dini Dalam Perspektif Neurosains: Robotik, Akademik, Dan Saintifik." Edukasia: Jumal Penelitian Pendidikan Islam, 13(2), 273304, 2019. https://doi.org/10.21043/edukasia.v13i2.3255.

_. "Perencanaan Dan Asesmen Perkembangan Pada Anak Usia Dini." Golden Age: Jurnal Ilmiah Tumbuh Kembang Anak Usia Dini, 2017. https://doi.org/10.14421/jga.2016.11-06.

Suyadi, and Hendro Widodo. "Millennialization of Islamic Education Based on Neuroscience in the Third Generation University in Yogyakarta Indonesia." Qudus International Journal of Islamic Studies, 7(1), 173-202, 2019. https://doi.org/10.21043/qiiis.v7i1.4922.

Umamah, Farida, Nurul Kamariyah, and Firdaus Firdaus. "Analisis Faktor Yang Mempengaruhi Keluhan Nyeri Punggung Pada Siswa Di SMP Laboratorium UNESA Surabaya." Jurnal Surya, 11(2), 28-37, 2019. https://doi.org/10.38040/js.v11i02.36.

Widiastuti, Ciptari, Totok Budi Santoso. "Pengaruh Core Stability Exercise Terhadap Kekuatan Otot-Otot Lumbal Akibat Pemakaian Sepatu Hak Tinggi Pada Sales Promotion Girl." Fakultas Ilmu Kesehatan Universitas Mubammadiyah Surakarta, 2013.

Yaniawati, Poppy. "Penelitian Studi Kepustakaan." Penelitian Kepustakaan (Liberary Research), 2020. 